\title{
Orographic influences on the Adriatic sirocco wind
}

\author{
Z. Pasarić, D. Belušić, and Z. B. Klaić \\ Department of Geophysics, Faculty of Science, University of Zagreb, Zagreb, Croatia
}

Received: 7 December 2006 - Revised: 16 April 2007 - Accepted: 21 May 2007 - Published: 29 June 2007

\begin{abstract}
Differences between meteorological fields over the Adriatic Sea as predicted by the mesoscale meteorological model ALADIN/HR and global ECMWF model, for sirocco episodes between November 2002 and September 2003, are analysed. Results indicate that the orography, namely Gargano Mountains and Apennines, may have a significant effect on the sirocco airflow. A brief discussion is given on the impact of the sirocco wind curl on the Western Adriatic Current (WAC).
\end{abstract}

Keywords. Meteorology and atmospheric dynamics (Mesoscale meteorology) - Oceanography: physical (Airsea interactions)

\section{Introduction}

Operational oceanography of the Mediterranean Sea has received significant attention in recent years (e.g. http://www. moon-oceanforecasting.eu). As one of the goals, a numerical forecasting system at basin, regional and shelf scales has been developed. The Adriatic Sea, in particular, is covered by a regional hydrodinamical model and several shelf models (Castellari, 2003), where the necessary boundary conditions are prescribed by simple one-way nesting between respective models (Zavatarelli and Pinardi, 2003). Due to operational constraints in the early stage of the efforts, the atmospheric forcing has been taken from the global ECMWF model having 0.5 degrees longitude and latitude resolution, which is far from enough to resolve fine structure of the Adriatic weather, known to be strongly influenced by local orography (e.g. Grubišić, 2004). The two most prominent types of Adriatic weather, namely those characterized by strong bora and strong sirocco winds, have so far received quite a different treatment. The bora is a northeasterly, relatively cold and gusty downslope windstorm blowing over the east Adriatic.

Correspondence to: Z. Pasarić

(pasaric@irb.hr)
A multitude of studies of the bora wind point to the crucial role of the influence that the orography, namely the Dinaric Alps, exerts on the incoming airflow from the northeast (e.g. Klaić et al., 2003; Belušić and Klaić, 2006). The surface jets and wakes are shown to be related to the mountain gaps and peaks, respectively (e.g. Belušić and Klaić, 2006), and their effect on the Adriatic Sea has been extensively documented (e.g. Orlić et al., 1994; Pullen et al., 2003). However, the sirocco wind has received much less attention, particularly concerning the orographic effects. This is, to a certain extent, understandable because the sirocco blows along the Adriatic and apparently has little interaction with the nearby mountain ranges (the Dinaric Alps and Apennines), which are also oriented in the along-shore direction. The Adriatic sirocco (locally called "jugo") is a branch of the Mediterranean sirocco and is sometimes differentiated from it due to specific local effects. It is generated by larger scale, usually synoptic weather patterns, but may also be due to mesoscale cyclone activity (Brzović, 1999; Brzović and Strelec Mahović, 1999). It can be classified under two general categories: cyclonic and anticyclonic sirocco. The more frequent, cyclonic type is related to the low pressure field northwest of the affected area which usually corresponds to the Genoa cyclone (Jurčec et al., 1996). Anticyclonic sirocco is primarily forced by the high pressure field above the Mediterranean.

In the present paper, the differences between the ECMWF fields and the corresponding output of the mesoscale meteorological model ALADIN (Geleyn et al., 2002) are analysed. The results point to the possibly significant effect of the mountain obstacles, namely the Gargano Mountains and the Apennines, on the sirocco airflow over the western part of the middle to northern Adriatic. The effect seems persistent and hence may produce a significant forcing on the Adriatic Sea, unresolved in the coarse resolution models. Possible atmospheric influence on the Western Adriatic Current (WAC) reversal, which is known to appear during episodes of sirocco wind (e.g. Poulain et al., 2004) is also discussed.

Published by Copernicus Publications on behalf of the European Geosciences Union. 

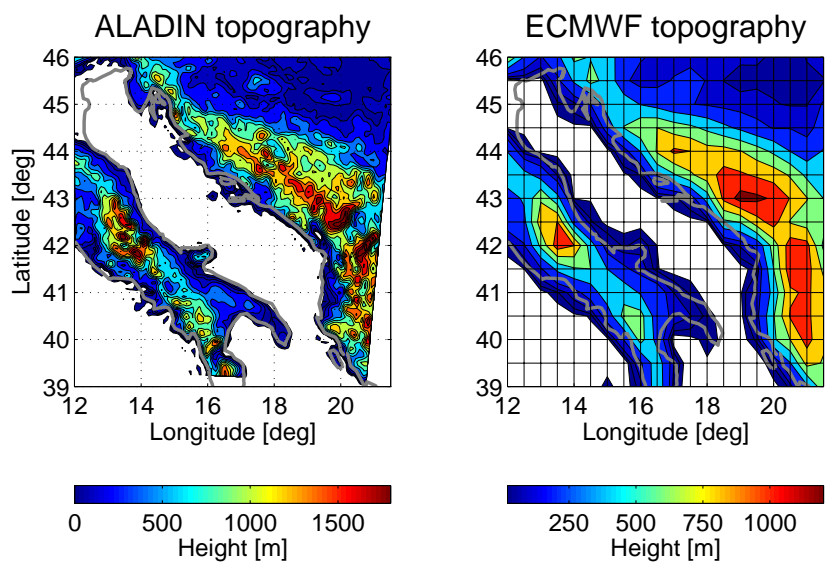

Fig. 1. ALADIN and ECMWF orography. The actual coastline is shown in grey. The 0.5 degrees ECMWF grid is shown on the right panel. The height levels shown are 20, 50, 100, 200, 400, $600, \ldots \mathrm{m}$.

\section{Methods}

The Croatian version of the operational mesoscale meteorological model ALADIN is run at the Croatian Meteorological and Hydrological Service at a horizontal resolution of $8 \mathrm{~km}$ (e.g. Ivatek-Sahdan and Tudor, 2004). Initial and boundary conditions are provided by the Meteo-France global model ARPEGE. The ALADIN output fields are given every $3 \mathrm{~h}$. The period from 1 November 2002 till 30 September 2003 is investigated in this study. The associated ECMWF fields, available every $6 \mathrm{~h}$, are trilinearly interpolated onto the ALADIN space-time grid. In order to extract sirocco situations three characteristic grid points are chosen in the northern part, and three in the southern part of the Adriatic. A total of 63 episodes are extracted as all instances where the six grid points have a wind from the fourth quadrant stronger than $8 \mathrm{~m} \mathrm{~s}^{-1}$. The threshold is chosen after some trial and error, but having in mind that winds over $8 \mathrm{~m} \mathrm{~s}^{-1}$ exert a strong influence on the sea. Mean differences between ALADIN and ECMWF modelled fields are calculated over these sirocco episodes.

\section{Results}

Due to the finer spatial resolution and consequently more realistic land-sea mask and orography (Fig. 1) ALADIN modelled fields are considered as referent (Fig. 2). Inspection of mean differences between ECMWF and ALADIN fields (Fig. 3) reveals that over the major part of the Adriatic the ECMWF model underestimates air temperatures. The discrepancies are the largest in the vicinity of the east coast where they reach $3^{\circ} \mathrm{C}$. This is primarily associated with the differences between the land-sea masks of the two models. The largest discrepancies at the west coast are some-
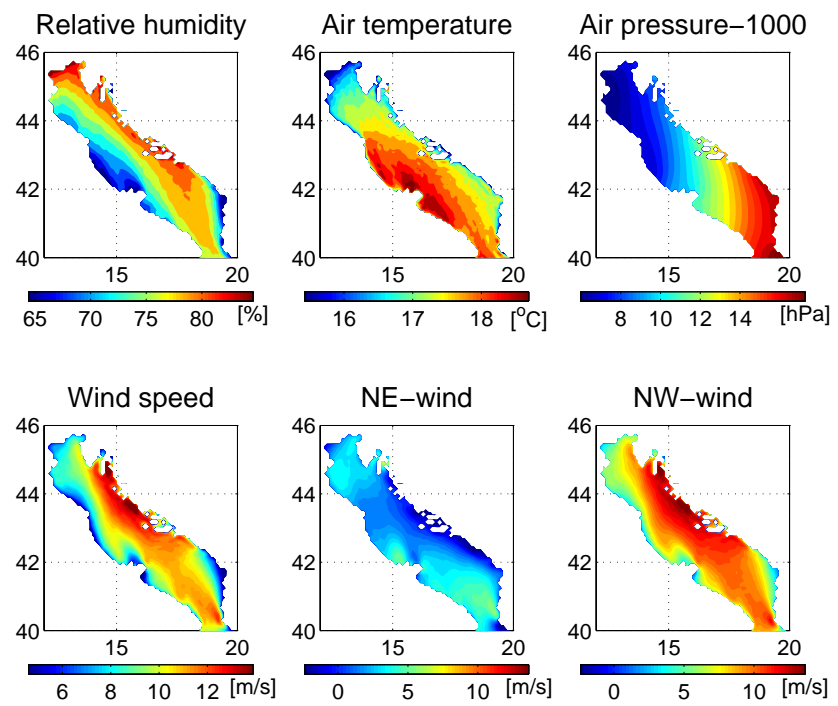

Fig. 2. ALADIN mean fields over the 63 sirocco episodes.
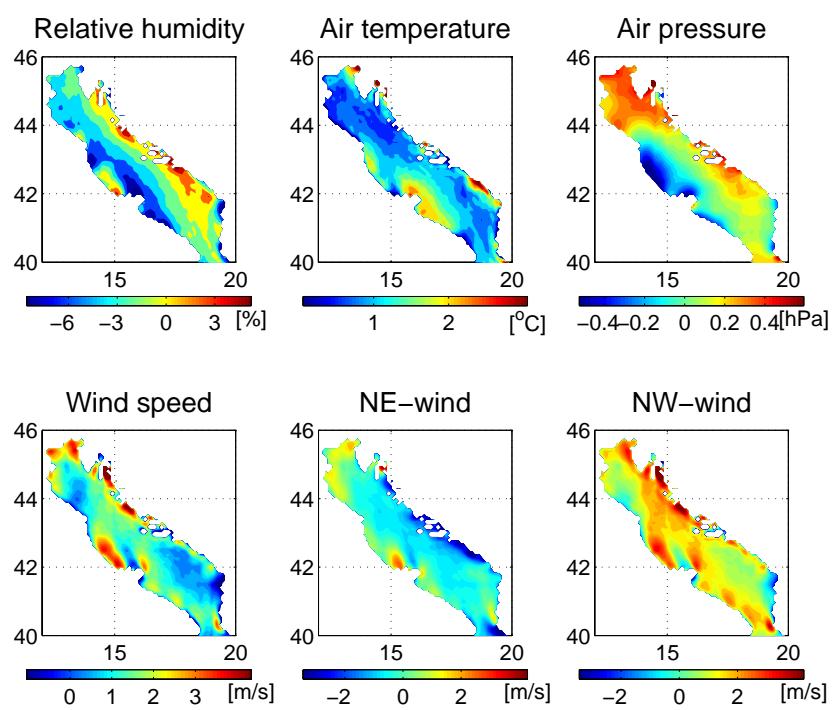

Fig. 3. ALADIN-ECMWF mean differences over the 63 sirocco episodes.

what smaller than those at the east coast. Again they are found close to the Italian coast and spread offshore around the Gargano peninsula.

The air pressure differences between the models (Fig. 3) are shaped as large contiguous areas of the same sign with amplitudes up to $2 \mathrm{hPa}$. The ECMWF model generally underestimates the air pressure over the northern Adriatic and along the middle and southern east Adriatic coast. On the other hand, the ECMWF predicted pressure is generally higher than in the ALADIN along the Italian coast south of Ancona. The region where the overprediction is particularly wide in the offshore direction extends from Ancona to the Gargano peninsula. 

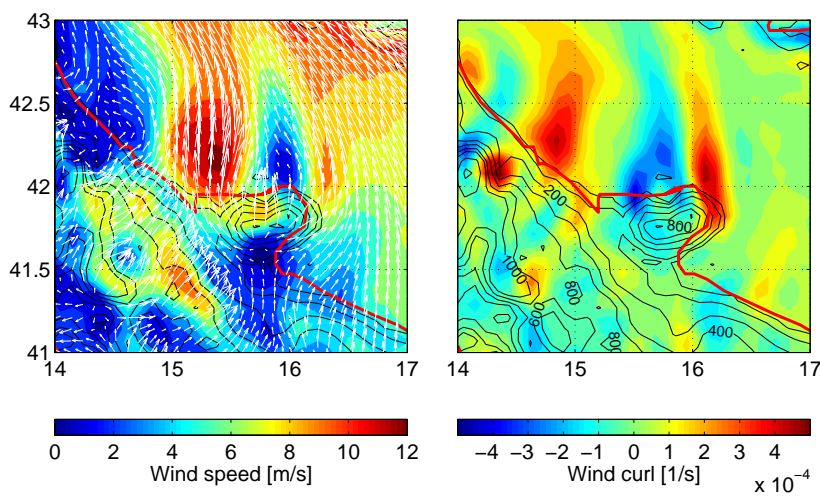

Fig. 4. ALADIN surface wind field (vectors and shaded; left panel) and surface wind curl (shaded; right panel) at 00:00 UTC on 28 December 2002 for the Gargano area. Orography contours shown are the same as in Fig. 1.

A comparison between the ALADIN and the ECMWF predicted sirocco winds shows discrepancies that are generally oriented along the main airflow direction. The ECMWF sirocco wind speeds are generally smaller than in the ALADIN (in some regions the differences are larger then $4 \mathrm{~m} \mathrm{~s}^{-1}$ ). Further, an interesting pattern with alternation of a jet-wake-jet structure is found north of Gargano. It seems to be a consequence of the blocking and splitting of the sirocco flow upstream of Gargano, which is almost an ideal 3-D obstacle. Accordingly, downstream of the mountain a typical pattern of airflow around a 3-D obstacle emerges with a wake in the central part of the lee and jets emanating from the obstacle edges (e.g. Smith, 1989; Grisogono and Enger, 2004). Additionally, the jet emanating from the western flank of Gargano is amplified due to the channelling along the valley between the Gargano and Apennines. A third amplifying effect on the western jet originates from the north-eastward downslope flow on the east side of the Apennines. The three superimposing mechanisms seem to result in the airflow convergence above the Adriatic northwest of Gargano, which is associated with the low pressure difference (Fig. 3). The jet penetrates far northward over the Adriatic.

Whether these processes are truly responsible for the western jet formation can most easily be seen by observing a specific sirocco situation, rather than the mean fields. Figure 4 depicts the situation with a strong sirocco flow over the Gargano area at 00:00 UTC on 28 December 2002. Flow blocking and splitting is quite clearly seen upstream of the Gargano Mountains. Consequently, the western flank of the flow is channelled through the valley that separates Gargano and the Apennines and is additionally amplified by the strong channelled downslope flow off the Apennines. The location of the western jet maximum is variable, depending on different incoming flow conditions, either within a sirocco episode, or from one episode to another. It generally shifts in the north-south direction. The wake in the lee of the Gargano
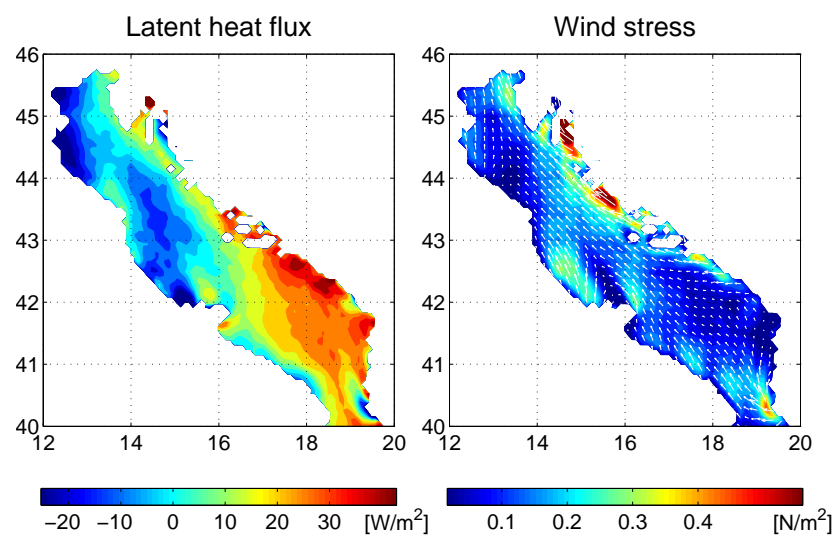

Fig. 5. ALADIN-ECMWF mean differences for latent heat flux and wind stress (vectors and shaded) over the 63 sirocco episodes.

Mountains appears behind the highest peak $(\sim 800 \mathrm{~m}$ at the ALADIN resolution). A trace of a weaker jet resulting from the flow splitting is located on the eastern side of the Gargano lee and merges with the primary sirocco maximum along the eastern Adriatic coast. The corresponding wind curl shows two prominent peaks at the western (negative curl) and eastern (positive curl) side of Gargano. They are clearly related to the jet-wake-jet structure. An additional positive maximum is located further to the northwest and corresponds to the northwest side of the western Gargano jet. Although quite prominent in this case, the curl maximum is not persistent over different sirocco cases due to the mentioned spatial variation of the western jet. Hence, contrary to the positive and negative wind-curl peaks around Gargano, it is not seen in the averaged plots (not shown). The regions with underpredicted sirocco winds are found over the eastern Adriatic too, and the differences in the wind speed have similar values as those over the greater Gargano area (Fig. 3).

Figure 5 depicts the mean differences between the surface latent heat flux and wind stress calculated from the ALADIN and ECMWF fields. During the sirocco events latent heat flux was negative over the whole Adriatic (not shown), meaning the sea is losing heat. Obviously, the differences are quite large north of Gargano. A negative-difference filament denotes the area where ALADIN loses more heat than ECMWF, which is related to a stronger wind in the western jet. The wind stress field also follows the max-min-max pattern related to the 3-D mountain airflow. Particularly interesting here is the stronger NW stress filament corresponding to the western jet, which may influence WAC. The density driven coastal current that generally outflows over the Italian shelf as a part of the general, Adriatic cyclonic circulation (Cushman-Roisin et al., 2001) can be reversed. 


\section{Discussion and conclusions}

It is known that the sirocco is stronger along the eastern than along the western Adriatic coast, due to the channelling effects of the surrounding mountains (e.g. Orlić et al., 1994; see Fig. 2). Hence, intuitively the sirocco wind-curl effect on the Adriatic would act to strengthen the usual Adriatic current structure, with a northwestward current along the eastern coast and southeastward along the western coast. However, it has been shown previously that the countercurrent, i.e. northwestward downwind current, appears along the western coast during sirocco episodes (Orlić et al., 1994; Poulain, 1999, 2001; Poulain et al., 2004). Using a numerical model of the Adriatic with idealized sirocco forcing, Orlić et al. (1994) point to a subtle interaction between the two mechanisms, namely the bottom-slope and wind-curl effect, as responsible for the appearance of the countercurrent. In this case, the bottom-slope effect, which supports downwind currents in the shallow parts of the basin, needs to be stronger than the wind-curl influence. Here we see that an additional and potentially quite significant effect may be traced in the detailed structure of the sirocco wind field along the western coast. The western Gargano jet acts in a way to enhance the anticyclonic, i.e. to reduce the cyclonic, curl along the western coast. The effect on the sea may be recognized through the surface wind stress field, where it is seen that the possible enhancement of the anticyclonic current vorticity is obtained through the interaction of the airflow with the local orography. Furthermore, the wind stress curl may prove important for the formation of mesoscale eddies in the sea which are observed in the vicinity of Gargano peninsula (Gačić and Artegiani, 2001), while stronger evaporation, and related latent heat flux, should influence the sea density field. Thus, certain important characteristics of the flow emerge when looking at the differences between the coarse and fine grid models, which are not so easily seen from the fine grid model fields alone. In this, the ECMWF model serves as a sort of low-pass spatial filter, thereby making the differences between the models similar to perturbations. It should also be mentioned that certain potentially relevant features occur in individual cases but are not seen after averaging. These processes are therefore not persistent, but may influence local sea circulation for a specific episode.

Further study should include detailed high-resolution airflow simulations of the Gargano area under sirocco conditions, in order to inspect additional enhancements of the flow details with increasing model resolution. Also, there are several other smaller-scale obstacles that might induce a similar effect on the airflow but these are not resolved at the horizontal resolution of $8 \mathrm{~km}$. An example is the Conero Promontory near Ancona, for which Poulain et al. (2004) report a case of unusual upwelling and current reversal associated with the positive wind vorticity. Moreover, coupling with an oceanographic model and examining the fine-scale sirocco forcing of the Adriatic, as well as the differences from using the coarse resolution model, is required.

Acknowledgements. The work was supported by the by Italian Ministry of Foreign Affairs (project ADRICOSM-EXT) and the Croatian Ministry of Science, Education and Sports (grants 1191193086-3085, 119-1193086-1323).

Topical Editor F. D' Andrea thanks two anonymous referees for their help in evaluating this paper.

\section{References}

Belušić, D. and Klaić, Z. B.: Mesoscale dynamics, structure and predictability of a severe Adriatic bora case, Meteorol. Z., 15, 157-168, 2006.

Brzović, N.: Factors affecting the Adriatic cyclone and associated windstorms, Contr. Atmos. Phys., 72, 51-65, 1999.

Brzović, N. and Strelec Mahović, N.: Cyclonic activity and severe jugo in the Adriatic, Phys. Chem. Earth, 24, 653-657, 1999.

Castellari, S.: ADRICOSM, Final Scientific Report, INGV, Bologna, 2003.

Cushman-Roisin, B., Gačić, M., Poulain, P.-M., and Artegiani, A. (Eds.): Physical Oceanography of the Adriatic Sea, Kluwer Academic Publishers, Dordrecht, 2001.

Gačić, M. and Artegiani, A.: Regional studies: Italian coastal waters, in: Physical Oceanography of the Adriatic Sea, edited by: Cushman-Roisin, B., Gačić, M., Poulain, P.-M., and Artegiani, A., Kluwer Accademic Publishers, Dordrecht, 182-189, 2001.

Geleyn, J. F., Banciu, D., Bubnova, R., Ihasz, I., Ivanovici, V., Le Moigne, P., and Radnoti, G.: The international project ALADIN: Summary of events October 1992-October 1993, LAM Newsletter, 23, 1992.

Grisogono, B. and Enger, L.: Boundary-layer variations due to orographic wave-breaking in the presence of rotation, Quart. J. Roy. Meteorol. Soc., 130, 2991-3014, 2004.

Grubišić, V.: Bora-driven potential vorticity banners over the Adriatic, Quart. J. Roy. Meteorol. Soc., 130, 2571-2603, 2004.

Ivatek-Šahdan, S. and Tudor, M.: Use of high-resolution dynamical adaptation in operational suite and research impact studies, Meteorol. Z., 13, 99-108, 2004.

Jurčec, V., Ivančan-Picek, B., Tutiš, V., and Vukičević, V.: Severe Adriatic jugo wind, Meteorol. Z., N.F., 5, 67-75, 1996.

Klaić, Z. B., Belušić, D., Grubišić, V., Gabela, L., and Ćoso, L.: Mesoscale airflow structure over the northern Croatian coast during MAP IOP 15 - a major bora event, Geofizika, 20, 23-61, 2003.

Orlić, M., Kuzmić, M., and Pasarić, Z.: Response of the Adriatic Sea to the bora and sirocco forcing, Cont. Shelf Res., 14, 91116, 1994.

Poulain, P.-M.: Drifter observations of surface circulation in the Adriatic Sea between December 1994 and March 1996, J. Mar. Syst., 20, 231-253, 1999.

Poulain, P.-M.: Adriatic Sea surface circulation as derived from drifter data between 1990 and 1999, J. Mar. Syst., 29, 3-32, 2001.

Poulain, P.-M., Mauri, E., and Ursella, L.: Unusual upwelling event and current reversal off the Italian Adriatic coast in summer 2003, Geophys. Res. Lett., 31, L05303, doi:10.1029/2003GL019121, 2004. 
Pullen, J., Doyle, J. D., Hodur, R., Ogston, A., Book, J. W., Perkins, H., and Signell, R.: Coupled ocean-atmosphere nested modeling of the Adriatic Sea during winter and spring 2001, J. Geophys. Res., 108(C10), 3320, doi:10.1029/2003JC001780, 2003.
Smith, R. B.: Hydrostatic airflow over mountains, Adv. Geophys., 31, 1-41, 1989.

Zavatarelli, M. and Pinardi, N.: The Adriatic Sea Modeling System: A nested approach, Ann. Geophys., 21, 345-364, 2003, http://www.ann-geophys.net/21/345/2003/. 